\title{
Access to myocardial revascularization procedures: Closing the gap with time?
}

\author{
Alain Vanasse ${ }^{* \dagger 1,2}$, Théophile Niyonsenga ${ }^{\dagger 3,2}$, Josiane Courteau ${ }^{\dagger 2}$ and \\ Abbas Hemiari ${ }^{\dagger 2}$
}

Address: ${ }^{1}$ Family Medicine Department, Faculty of Medicine, Université de Sherbrooke, 3001, 12th Avenue North, Sherbrooke (QC), J1H 5N4, Canada, 2 PRIMUS Group, Clinical Research Center, Sherbrooke University Hospital, Sherbrooke (QC), Canada and ${ }^{3}$ Epidemiology \& Biostatistics, Stempel School of Public Health, Florida International University (FIU), USA

Email: Alain Vanasse* - alain.vanasse@usherbrooke.ca; Théophile Niyonsenga - niyonsen@fiu.edu; Josiane Courteau - josiane.courteau@chus.qc.ca; Abbas Hemiari - abbas.hemiari@chus.qc.ca

* Corresponding author †Equal contributors

Published: 08 March 2006

BMC Public Health2006, 6:60 doi:10.1 I86/1471-2458-6-60
Received: 09 January 2006

Accepted: 08 March 2006

This article is available from: http://www.biomedcentral.com/I47I-2458/6/60

(C) 2006Vanasse et al; licensee BioMed Central Ltd.

This is an Open Access article distributed under the terms of the Creative Commons Attribution License (http://creativecommons.org/licenses/by/2.0), which permits unrestricted use, distribution, and reproduction in any medium, provided the original work is properly cited.

\begin{abstract}
Background: Early access to revascularization procedures is known to be related to a more favorable outcome in myocardial infarction (Ml) patients, but access to specialized care varies widely amongst the population. We aim to test if the early gap found in the revascularization rates, according to distance between patients' location and the closest specialized cardiology center (SCC), remains on a long term basis.
\end{abstract}

Methods: We conducted a population-based cohort study using data from the Quebec's hospital discharge register (MED-ECHO). The study population includes all patients 25 years and older living in the province of Quebec, who were hospitalized for a MI in 1999 with a follow up time of one year after the index hospitalization. The main variable is revascularization (percutaneous transluminal coronary angioplasty or a coronary artery bypass graft). The population is divided in four groups depending how close they are from a SCC $(<32 \mathrm{~km}, 32-64 \mathrm{~km}, 64-105 \mathrm{~km}$ and $\geq 105$ $\mathrm{km})$. Revascularization rates are adjusted for age and sex.

Results: The study population includes II,802 individuals, $66 \%$ are men. The one-year incidence rate of $\mathrm{Ml}$ is 244 individuals per 100,000 inhabitants. At index hospitalization, a significant gap is found between patients living close $(<32 \mathrm{~km})$ to a SCC and patients living farther $(\geq 32 \mathrm{~km})$. During the first year, a gap reduction can be observed but only for patients living at an intermediate distance from the specialized center $(64-105 \mathrm{~km})$.

Conclusion: The gap observed in revascularization rates at the index hospitalization for $\mathrm{Ml}$ is in favour of patients living closer $(<32 \mathrm{~km})$ to a SCC. This gap remains unchanged over the first year after an Ml except for patients living between 64 and $105 \mathrm{~km}$, where a closing of the gap can be noticed.

\section{Background}

In Canada, cardiovascular events represent a major health burden similar to what is observed in other developed countries. Myocardial infarction (MI) accounts for a large 
percentage of these events [1]. Although practice guidelines regarding MI management have been widely published $[2,3]$, regional disparities in managed cares and outcomes are still observed in Canada [4-15], as well as in other countries [16-23].

Early percutaneous transluminal coronary angioplasty (PTCA) has been given much greater priority in recent years [3]. According to Health Canada, the number of PTCA done in Canada increased of 36\% between 1994/95 and 2000/01 [24]. Moreover, patients suffering from a MI, who received an invasive cardiac procedure such as coronary angiography or revascularization during the first hospitalization, were less likely to be readmitted later for cardiac reasons [25]. Invasive cardiac procedures require technical facilities and a professional expertise available only in specialized cardiology centers, logically privileging people living closer. In fact, both the availability of these services in the hospital initially admitting the patient and the geographical proximity to these services are factors determining their use $[5,26]$. Thus patients from rural areas are disadvantaged as they are less likely to get a diagnostic and cardiac procedures [27], or must wait longer to access these procedures [28].

To our knowledge, only few studies have been published reporting results on the gap in revascularization rates according to the distance of patient's location and specialized cardiology centers (SCC). Amongst these, Scott et al [29] analyzed access to potential intravenous thrombolysis for stroke using crow-flight distances of 32, 64 and 105 $\mathrm{km}$ around Canadian hospitals. Vanasse et al [4] studied management and outcomes of acute coronary syndrome stratified by distance to SCC. This latter study showed that distances to SCC have an impact on the likelihood of receiving an invasive cardiac procedure at index hospitalization for patients suffering from an acute coronary syndrome. However, no one has studied the evolution of the gap over a one year period.

We hypothesize that MI patients living within a short distance from SCC will have a greater proportion of revascularization procedures compared to patients living farther, and that the gap will decrease with time, as patients living farther will have access to SCC on an elective basis in the year following their first hospitalization.

The aim of this paper is to test if the early gap observed in the revascularization rates according to distance between the patients' location and the closest SCC remains on a long term basis. The first objective of this study is to describe and compare the revascularization rates (PTCA or coronary artery bypass graft (CABG)) of patients with $\mathrm{MI}$, according to distance categories ( $<32 \mathrm{~km}, 32-64 \mathrm{~km}, 64-$ $105 \mathrm{~km}$ and $\geq 105 \mathrm{~km}$ ). The second objective is to measure the evolution of the gap between groups over time $(3,6$, 9 , and 12 months).

\section{Methods \\ Design}

We conducted a population-based cohort study using secondary data analysis from the Quebec's hospital discharge register: "Maintenance et Exploitation des Données pour l'Étude de la Clientèle Hospitalière (MED-ECHO) ». This register provides administrative data on all patients hospitalized in an acute care hospital in the province of Quebec. Studies confirming the accuracy of the administrative data concerning myocardial infarction have previously been published [30,31]. The follow-up period time is 12 months for every patient entered in the cohort.

\section{Studied population}

The study population includes all patients 25 years and older living in the province of Quebec, who were hospitalized for a MI (code 410 of the IDC-9 International Disease Classification, $9^{\text {th }}$ revision) between January $1^{\text {st }} 1999$ and December $31^{\text {st }} 1999$. The "index hospitalization" is the first hospitalization during the study period. If the care management occurred over several contiguous hospitalizations involving hospital transfers, the index hospitalization refers to the entire episode. Patients with a MI in the year preceding the index hospitalization are excluded in order to include only new or stable MI cases. Patients from Outaouais are excluded because of its close proximity to a SCC located in Ontario, a contiguous province for which data is not available in the MED-ECHO register. Because of the very sparse population and a different care management pattern in the Northern Quebec region, patients from this region are excluded. Patients with an unknown postal code are also excluded.

The population is divided in four study groups. The geographic grouping of patients is based on the crow-flight distance between their living dwelling and the nearest SCC (<32 km, 32-64 km, 64-105 km and $\geq 105 \mathrm{~km}$ ). We selected these cut points based on estimated travel times of 60,90 and 120 minutes respectively to cover a distance of 32, 64 and $105 \mathrm{~km}[29,32]$. The localization of the patient's area and the specialized cardiology center is defined by the geometrical centroid of their postal codes.

\section{Data sources}

Patient-data were obtained from Quebec's hospital discharge register (MED-ECHO). Each patient was then spatially referenced by his/her postal code using data from DMTI Spatial [33]. The list of SCC was obtained from the Quebec tertiary cardiology network of the Quebec Ministry of Health and Social Services [34]. The geographic coordinate system used for the cartographic presentation was GCS North American 1983. 


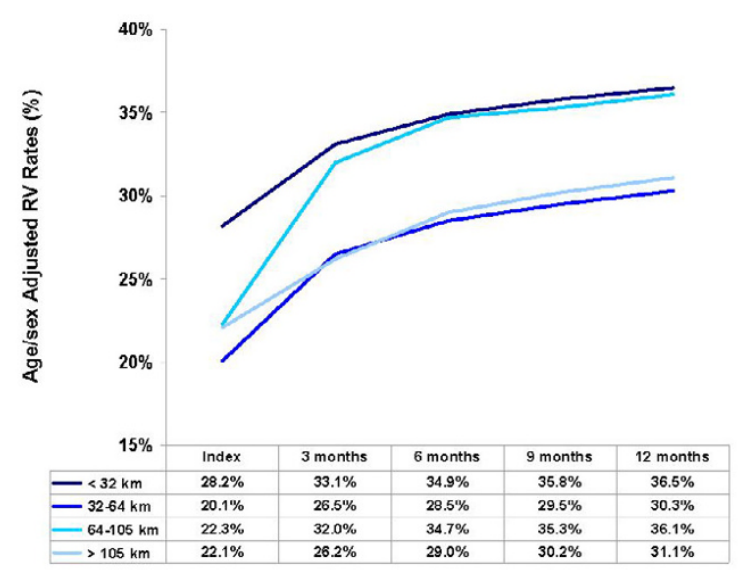

Figure I

Age and sex adjusted revascularization (RV) rates at index hospitalization, 3, 6, 9 and 12 months after the index admission by distance from residence to nearest specialized cardiology center $(\mathrm{n}=\mathrm{I} \mid \mathrm{I}, 802)$.

\section{Studied variables}

Patients are considered to have undergone a revascularization procedure at index hospitalization if there is a mention of PTCA or CABG as coded in the Quebec's hospital discharge registers (Canadian Classification of Diagnostic, Therapeutic, and Surgical Procedures (CCP) beginning with 480 to 483 ). Revascularization rates are also established over specific time periods, namely at 3, 6, 9 and 12 months following the index hospitalization.

\section{Analyses}

Descriptive analyses by distance categories from dwelling to nearest specialized cardiology center were done. We used the Pearson $\chi^{2}$ test for comparisons between proportions. All revascularization rates are adjusted for age and sex. A cartographic representation of the adjusted rates is also presented using specific catchment areas of $<32 \mathrm{~km}$; 32-64 km; 64-105 km; and $\geq 105 \mathrm{~km}$. Statistical analyses were done using SAS 9.1 [35] and cartographic representations were made using ArcGIS 9.0 [36].

\section{Ethical considerations}

This project was approved by the Sherbrooke University Hospital Ethics Board and the Commission d'accès à l'information du Québec.

\section{Results}

A total of 12,646 individuals were hospitalized for MI in Quebec between January $1^{\text {st }} 1999$ and December $31^{\text {th }}$ 1999. Of those, some patients were excluded: 9 because they were less than 25 years old, 289 because they had a MI the year prior to index hospitalization, 544 because they were living in the sparsely populated northern region or in the Outaouais region, and 2 because there was an error in their code of residence. Therefore, the study population totalled 11,802 individuals, of which $66 \%(n=$ $7733)$ were men. The average age was 66.5 years $( \pm 13.8)$. The one-year incidence rate was 244 individuals per 100,000 inhabitants.

The age and sex adjusted revascularization rates differed significantly $(p<0.0001)$ amongst groups and over time (Figure 1), varying from $20.1 \%$ to $28.2 \%$ at index hospitalization and from $30.3 \%$ to $36.5 \%$ one year after. Higher rates of revascularization are found in the patients' group closer to a SCC at all points in time. At index hospitalization, statistically significant gaps can be observed between the patients' group living close to a SCC $(<32 \mathrm{~km})$ and the other groups $(\mathrm{p}<0.0001)$. During the first year, a reduction of the gap can be found but only for patients living at an intermediate distance from the specialized center (64$105 \mathrm{~km}$ ). In fact, the gap in revascularization rates between patients living at less than $32 \mathrm{~km}$ and those living between 64 and $105 \mathrm{~km}$ from a SCC is not statistically significant after 3 months ( $\mathrm{p}=0.4812$ ), but significant differences can be observed for the two other patients' groups ( $\mathrm{p}<.0001)$, creating a halo pattern of low revascularization rates by patients living between 32 and $64 \mathrm{~km}$ from a SCC. This halo pattern is more easily demonstrated with the cartographic representations in Figure 2 and Figure 3.

\section{Discussion}

Revascularization rates in the province of Quebec in 1999, as found in this study, are similar to others previously presented in Quebec [12]. The results showed above support the first part of our hypothesis. In fact, the gap in the revascularization rates between the four groups of patients at index hospitalization benefits patients living at less than $32 \mathrm{~km}$ from a SCC. A frequent explanation put forward in the literature to account for use of invasive cardiac procedures is accessibility to facilities performing such procedures [37].

The negative relationship between revascularization rates and distance to specialized centers has also been noticed in different countries $[16,20,21,23]$ including Canada $[5,7,11,13]$. However the second part of our hypothesis is found to be partly true. Indeed, we can observe a complete closure of the gap for one of the groups living farther but the two others remain unchanged at one year. In fact, only the patients' group living within intermediate distances (64-105 km) to a SCC will close the gap over time. Strangely enough, the patients' group living between 32 and $64 \mathrm{~km}$ will experience the same lasting gap than the group of patient living farther than $105 \mathrm{~km}$. This result cannot be attributed to a demographic difference between the four groups as age and sex adjusted rates have been 


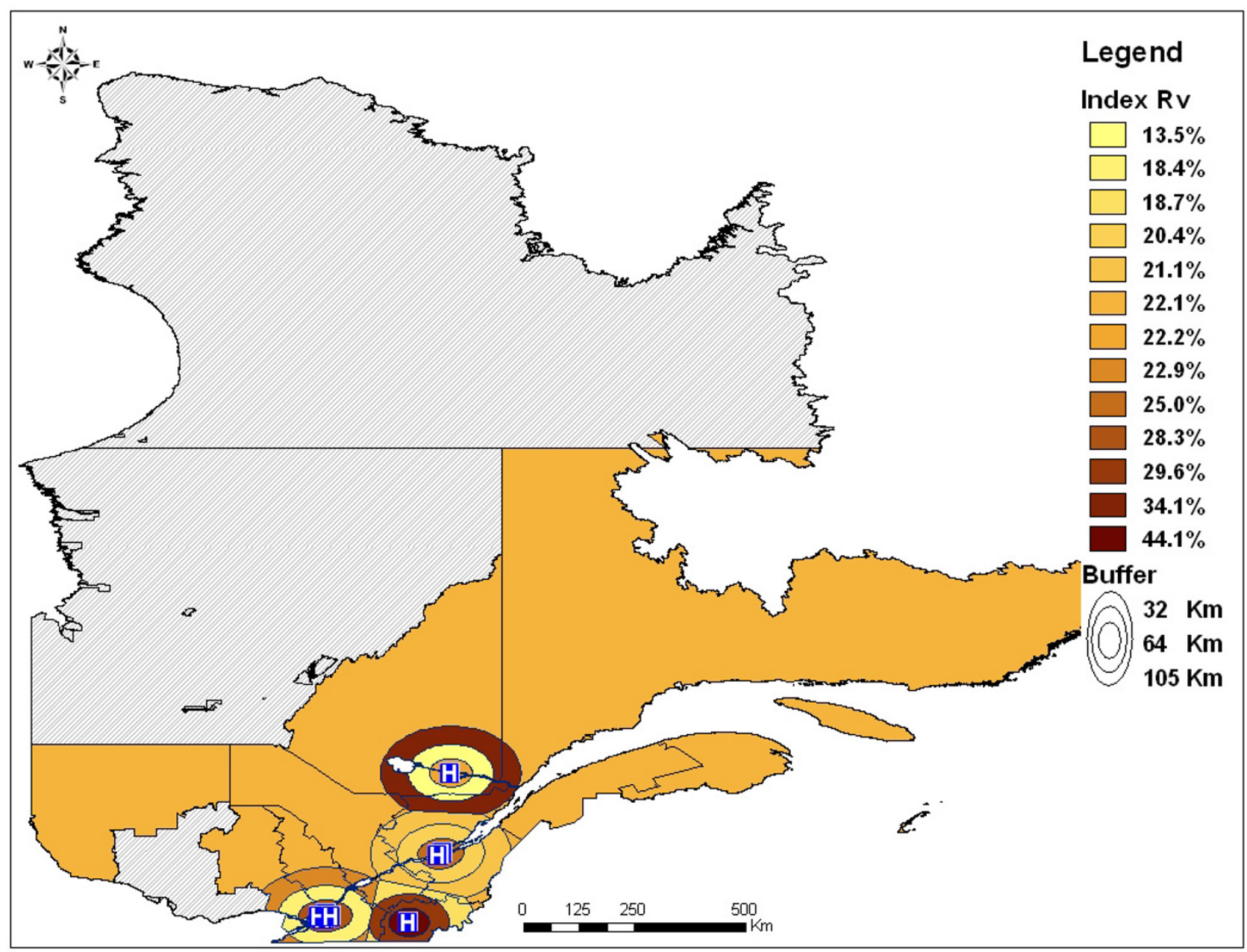

\section{Figure 2}

Age and sex adjusted revascularization (RV) rates at index hospitalization by distance from residence to specialized cardiology centers $(n=11,802)$.

presented. To our knowledge, it is the first time that the halo pattern revealed by the map has been described. Therefore, more comprehensive studies to fully understand this phenomenon are needed.

Piché et al argued that the relation between distance and access to care varies with the medical situation (severity, urgency, etc.) $[38,39]$. If we can logically hypothesize that patients in the 64-105 km radius of location may be easily transferred by their local physicians for non urgent revascularization than the patients living farther, no evident explanation can be offered for patients living in the $32-64 \mathrm{~km}$ radius.

In order to reduce bias in the comparison of each group, death rates were also measured at each point in time and were found to be not statistically different at the index hospitalization $(p=0.2628)$ and at one year $(p=0.1659)$ (data not presented). Bias can also result from an underestimation of deaths at index hospitalization in groups living farther and may possibly explain some of the differences. In fact, sicker people living in remote regions possibly die before even being admitted to the hospital. Increase in the time between onsets of symptoms to treatment (onset-to-door) has previously been reported in rural regions [40].

To better understand geographical disparities in healthcare management, more comprehensive exploration of socio-demographic variables' contribution is needed. Rurality is one of these variables that seems important to consider [41]. Indeed, rural populations differ from urban 


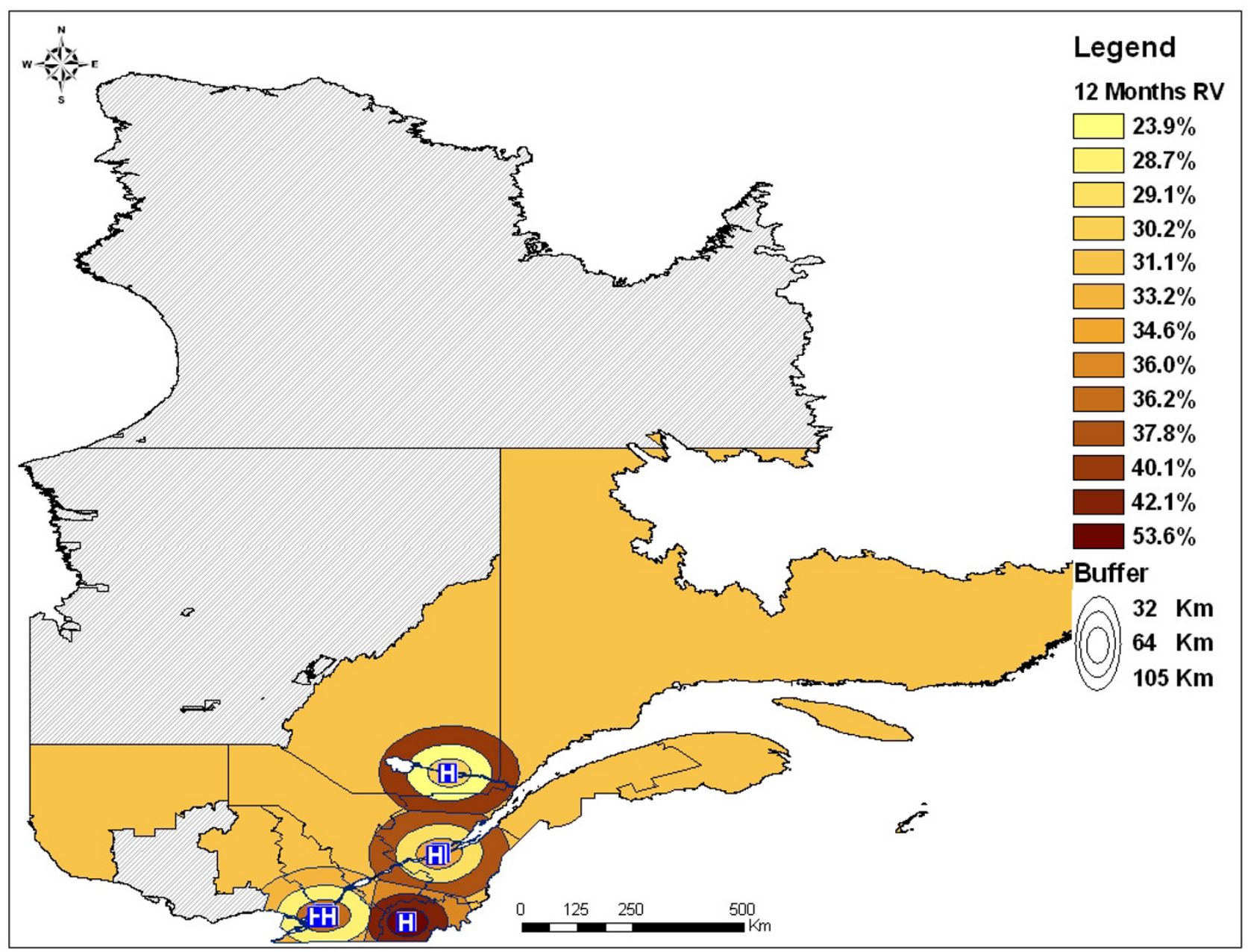

Figure 3

Age and sex adjusted revascularization (RV) rates at 12 months by distance from residence to specialized cardiology centers ( $\mathrm{n}$ $=11,802)$.

ones not only in geographical access to care [42] but also by their cultural and socioeconomic backgrounds. Other possible variables that can explain heterogeneity in MI management include social and material deprivation indices [43], medical care and professional attributes including academic affiliation and year of graduation for family physicians and cardiologists [15].

The use of administrative data has some limitations. Even though Quebec's hospital discharge register has been used for epidemiological studies on acute myocardial infarction [30,31], the follow-up of the hospital's care episode spread out over different care institutions requires an algorithm for which the accuracy needs to be further validated. Another limitation to take into account is the use of the crow-flight distance as estimated traveling time between the place of living and the care center [44,45]. The use of this proxy may not be valid for all regions in the province.

\section{Conclusion}

According to distance categories, significant gaps were observed in revascularization rates after a MI at index hospitalization. The gaps remained significant during the first year after a MI, except for patients living at an intermediate distance (64-105 km) from the cardiology center. This halo pattern can be easily noticed on a thematic map.

\section{Competing interests}

This project has benefited from an unrestricted grant by Merck Frosst Canada Ltd. 


\section{Authors' contributions}

$\mathrm{AV}, \mathrm{TN}$ conceived the study, JC and TN performed the analyses. AV, TN and JC wrote the manuscript and $\mathrm{AH}$ produced the maps. All authors read and approved the final version of the manuscript.

\section{Acknowledgements}

This project was subsidized by the GEOIDE Network of Centers of Excellence and Merck Frosst Canada Ltd. The principal investigator was supported by the Department of Family Medicine, Université de Sherbrooke; the Clinical Research Center, Sherbrooke University Hospital; and the Fonds de la Recherche en Santé du Québec.

\section{References}

I. Canadian Heart foundation (Fondation des maladies du Cœur du Canada): Le Fardeau croissant des maladies cardiovasculaires et des accidents vasculaires cérébraux au Canada Ottawa, Canada; 2003.

2. Mehta RH, Montoye CK, Gallogly M, Baker P, Blount A, Faul J, Roychoudhury C, Borzak S, Fox S, Franklin M, Freundl M, Kline-Rogers E, LaLonde T, Orza M, Parrish R, Satwicz M, Smith MJ, Sobotka P, Winston S, Riba AA, Eagle KA, for the GAP Steering Committee of the American College of Cardiology: Improving quality of care for acute myocardial infarction: the guidelines applied in practice (GAP) initiative. JAMA 2002, 287( I 0): 1269-76.

3. Ryan TJ, Antman EM, Brooks NH, Califf RM, Hillis LD, Hiratzka LF, Rapaport E, Riegel B, Russell RO, Smith EE 3rd, Weaver WD, Gibbons RJ, Alpert JS, Eagle KA, Gardner TJ, Garson A Jr, Gregoratos G, Ryan T], Smith SC Jr: 1999 update: ACC/AHA guidelines for the management of patients with acute myocardial infarction. A report of the ACC/AHA Task Force on practice guidelines. J Am Coll Cardiol I999, 34(3):890-9| I.

4. Vanasse A, Niyonsenga T, Courteau J, Grégoire JP, Hemiari A, Loslier J, Bénié G: Spatial variation in the management and outcomes of acute coronary syndrome. BMC Cardiovascular Disorders 2005, 5:21

5. Alter DA, Austin PC, Tu JV: Community factors, hospital characteristics and inter-regional outcome variation following acute myocardial infarction in Canada. Can J Cardiol 2005, 2I(3):247-255.

6. Faris PD, Grant FC, Galbraith PD, Gong Y, Ghali WA: Diagnostic cardiac catheterization and revascularization rates for coronary heart disease. Can J Cardiol 2004, 20(4):39|-397.

7. Filate WA, Johansen HL, Kennedy CC, Tu JV: Regional variations in cardiovascular mortality in Canada. Can J Cardiol 2003, I (1 I ): $1241-1248$.

8. Ghali WA, Quan H, Shrive FM, Hirsch GM: Outcomes after coronary artery bypass graft surgery in Canada: $1992 / 93$ to 2000/ 0I. Can J Cardiol 2003, I 9(7):774-780.

9. Hall RE, Tu JV: Hospitalization rates and length of stay for cardiovascular conditions in Canada, 1994 to 1999. Can J Cardiol 2003, I (1 (10): ||23-3|.

10. Jamal SM, Shrive FM, Ghali WA, Knudtson ML, Eisenberg MJ: In-hospital outcomes after percutaneous coronary intervention in Canada: 1992/93 to 2000/0I. Can J Cardiol 2003, 19(7):782-789.

II. Pilote L, Beck CA, Karp I, Alter D, Austin P, Cox J, Humphries K, Jackevicius $\mathrm{C}$, Richard $\mathrm{H}$, Tu JV: Secondary prevention after acute myocardial infarction in four Canadian provinces, 19972000. Can / Cardiol 2004, 20(I):61-7.

12. Pilote L, Merrett P, Karp I, Alter D, Austin PC, Cox J, Johansen H, Ghali W, Tu JV: Cardiac procedures after an acute myocardial infarction across nine Canadian provinces. Can J Cardiol 2004, 20(5):49I-500.

13. Rodrigues EJ, Simpson E, Richard H, Pilote L: Regional variation in the management of acute myocardial infarction in the province of Quebec. Can J Cardiol 2002, I 8( I0): I067-76.

14. Tu JV, Austin PC, Filate WA, Johansen HL, Brien SE, Pilote L, Alter DA: Outcomes of acute myocardial infarction in Canada. Can J Cardiol 2003, I 9(8):893-90I.

15. Tu K, Cong Y, Austin PC, Jaakkimainen L, Tu J: An overview of the types of physicians treating acute cardiac conditions in Canada. Can J Cardiol 2004, 20(3):282-29I.
16. Dunn NR, Arscott A, Thorogood M, Faragher B, de Caestecker L, MacDonald TM, McCollum C, Thomas S, Mann RD: Regional variation in incidence and case fatality of myocardial infarction among young women in England, Scotlank and Wales. Journal of Epidemiology \& Community Health 2000, 54(4):293-298.

17. Garg PP, Landrum MB, Normand SL, Ayanian JZ, Hauptman PJ, Ryan TJ, McNeil BJ, Guadagnoli E: Understanding individuals and small area variation in the underuse of coronary angiography following acute myocardial infarction. Medical Care 2002, 40(7):614-626.

18. Giugliano RP, Llevadot J, Wilcox RG, Gurfinkel EP, McCabe $\mathrm{CH}$, Charlesworth A, Thompson SL, Antman EM, Braunwald E: Geographic variation in patient and hospital characteristics, management, and clinical outcomes in ST-elevation myocardial infarction treated with fibrinolysis. European Heart Journal 200I, 22(18): 1702-1715

19. Guadagnoli E, Landrum MB, Normand SL, Ayanian JZ, Garg P, Hauptman PJ, Ryan TJ, McNeil BJ: Impact of underuse, overuse, and discretionary use on geographic variation in the use of coronary angiography after acute myocardial infarction. Medical Care 200I, 39(5):446-58

20. Heller RF, O'Connell RL, Lim LL, Atallah A, Lanas F, Joshi P, Tatsanavivat $P$ : Variation in stated management of acute myocardial infarction in five countries. International Journal of Cardiology 1999, 68(I):63-67.

21. Krumholz HM, Chen J, Rathore SS, Wang Y, Radford MJ: Regional variation in the treatment and outcomes of myocardial infarction: investigating New England's advantage. American Heart Journal 2003, 146(2):242-249.

22. Subramanian U, Weinberger M, Eckert GJ, L'Italien GJ, Lapuerta $P$, Tierney W: Geographic variation in health care utilization and outcomes in veterans with acute myocardial infarction. J Gen Intern Med 2002, I7(8):604-6II.

23. Viik-Kajander M, Moltchanova E, Salomaa V, Tuomilehto J, Ketonen M, Palomaki P, Miettinen H, Pyorala K, Karvonen M, FINMONICA AMI Register Study Group: Geographical variation in the incidence of acute myocardial infarction in eastern Finland-a Bayesian perspective. Annals of Medicine 2003, 35(I):43-50.

24. Health Canada, Centre for Chronic Disease Prevention and Control. Canadian Cardiovascular Society. Heart and Stroke Foundation of Canada: The Growing Burden of Heart Disease and Stroke in Canada 2003. 2003 [http://www.crdinfobase.ca/crdbook/]. Ottawa, Canada

25. Maynard C, Every NR, Weaver WD: Factors associated with rehospitalization in patients with acute myocardial infarction. Am J Cardiol 1997, 80(6):777-9.

26. Pilote L, Califf RM, Sapp S, Miller DP, Mark DB, Weaver WD, Gore JM, Armstrong PW, Ohman EM, Topol EJ: Regional variation across the United States in the management of acute myocardial infarction. New England Journal of Medicine 1995, 333(9):565-72.

27. Heller RF, O'Connell RL, D'Este C, Lim LLY, Fletcher PJ: Differences in cardiac procedures among patients in metropolitan and non-metropolitan hospitals in New South Wales after myocardial infarction and angina. Aust $J$ rural health 2000, 8:310-17.

28. Marrugat J, Sanz G, Masiá R, Valle V, Molina L, Cardona M, Sala J, Seres L, Szescielinski L, Albert X, Lupon J, Alonso J, for the RESCATE investigators: Six-month outcomes in patients with myocardial infarction initially admitted to tertiary and nontertiary hospitals. JACC 1997, 30(5): I187-92.

29. Scott PA, Temovsky C], Lawrence K, Gudaitis E, Lowell MJ: Analysis of Canadian population with potential geographic access to intravenous thrombolysis for acute ischemic stroke. Stroke 1998, 29:2304-I0.

30. Levy AR, Tamblyn RM, Fitchett D, McLeod PJ, Hanley JA: Coding accuracy of hospital discharge data for elderly survivors of myocardial infarction. Can / Cardiol I999, I 5( I I): 1277-82.

31. Petersen LA, Wright SM, Normand SLT, Daley J: Positive predictive value of the diagnosis of acute myocardial infarction in an administrative database. J Gen Intern Med 1999, 14:555-8.

32. Winters RC, Hendey GW, Bivins $\mathrm{H}$ : Helicopter versus ground ambulance transport: is a helicopter actually faster? Acad Emerg Med 1998, 5:442.

33. DMTI Spatial Data Delivery System, CanMap Streetfiles and PostCode files 2000 [http://www.dmtispatial.com]. 
34. Quebec tertiary cardiology network. Quebec Ministry of Health and Social Services [http://www.rqct.qc.ca/]. Accessed in February 2006

35. SAS Systems for Windows. Release 9.I. SAS Institute Inc., Cary, NC.

36. ArcGIS. Release 9.0. ESRI. Redlands, CA.

37. Giles WH, Anda RF, Casper ML, Escobedo LG, Taylor HA: Race and sex differences in rates of invasive cardiac procedures in US hospitals. Data from the national hospital discharge survey. Arch Intern Med 1995, 1 55:318-24.

38. Piché J, Côté H: Développement et validation d'un indicateur d'accessibilité géographique aux ressources hospitalières. Ministère de la Santé et des Services Sociaux, Direction générale de la planification et de l'évaluation, collection Méthodologie et Instrumentation 1997, n I I:29 [http:// www.msss.gouv.qc.ca/]. et annexes

39. Bowerman R: Evaluating and Improving the Accessibility of Primary Health Care Service. In Ph.D. Thesis University of Waterloo; 1997.

40. Amiot MA, Vanasse A: Délais de traitement dans l'infarctus du myocarde. Les Actualités du cœur 1997, 2(2):.

41. Ricketts TC: Rural health in the United States New York USA: Oxford University Press. Oxford University Press; 1999.

42. Alter DA, Naylor CD, Austin PC, Benjamin TB, Vu JV: Geography and service supply do not explain socioeconomic gradients in angiography use after acute myocardial infarction. CMAJ 2003, 168(3):26I-4.

43. Pampalon R, Raymond G: A deprivation index for health and welfare planning in Quebec. Chronic Disease in Canada 2000, 2I(3): 104-13.

44. Phibbs CS, Luft HS: Correlation of travel time on roads versus straight line distance. Medical Care Research and Review 1995, 52:532-42.

45. Jordan $\mathrm{H}$, Roderick $\mathrm{P}$, Martin D, Barnett S: Distance, rurality and the need for care: access to health services in South West England. International Journal of Health Geographics 3(21):. 2004 Sep 29

\section{Pre-publication history}

The pre-publication history for this paper can be accessed here:

http://www.biomedcentral.com/1471-2458/6/60/prepub http.//www. bion 